\title{
Clinical and Angiographic Outcomes After Multi-Link PENTA Stent Implantation in Japanese Patients With Coronary Artery Disease
}

\author{
Hisataka SASAO, ${ }^{1} \mathrm{MD}$, Hitoko OGATA, ${ }^{1} \mathrm{MD}$, and Daisuke HoTTA, ${ }^{1} \mathrm{MD}$
}

\begin{abstract}
SUMMARY
The flexibility of the Multi-Link (ML) PENTA stent with platform 0.09 to $0.12-\mathrm{mm}$ thick struts and $12 \%$ to $16 \%$ metal/artery coverage was improved to facilitate safe delivery in complex coronary lesions. The present study was designed to evaluate the clinical (9-month) and angiographic (6-month) results of the ML PENTA stent in complex coronary lesions (modified American College of Cardiology/American Heart Association lesion type $\mathrm{B} 2$ or $\mathrm{C}$ ) and to determine independent factors correlated with target lesion revascularization. The study population consisted of 86 consecutive patients who had undergone successful coronary ML PENTA stent implantation for coronary artery disease from May 2003 to July 2004 in our hospital. During the follow-up period, cardiac events were documented in $21(24.4 \%)$ of the 86 patients. Target lesion revascularization was required in $16(18.6 \%)$ of the 86 patients. Single logistic regression analysis showed that target lesion revascularization was significantly correlated with lesion length $>2.0 \mathrm{~cm}$, residual percent diameter stenosis after the procedure $>20 \%$, and multiple stents. Multiple logistic regression analysis showed that residual percent diameter stenosis after procedure $>20 \%(P=0.0125$, odds ratio $=11.585)$ was the significant explanatory factor of target lesion revascularization. The results of the present study suggest that 9-month clinical and 6-month angiographic outcomes in patients with coronary artery disease treated using the ML PENTA stent were excellent and target lesion revascularization after coronary ML PENTA stent implantation was influenced by residual percent diameter stenosis after the procedure. (Int Heart J 2005; 46: 997-1006)
\end{abstract}

Key words: Multi-Link PENTA stent, Target lesion revascularization, Residual percent diameter stenosis

THE flexibility of the Multi-Link (ML) PENTA stent (Guidant, Santa Clara, California) with platform 0.09 to 0.12 -mm-thick struts and $12 \%$ to $16 \%$ metal/ artery coverage, which is a recently developed stent, has been improved to facilitate safe delivery in complex coronary lesions and the stent maintains sidebranch access with the possibility to expand the cell toward the side branch up to

From the ${ }^{1}$ Department of Cardiology, Sapporo Social Insurance General Hospital, Hokkaido, Japan.

Address for correspondence: Hisataka Sasao, MD, Department of Cardiology, Sapporo Social Insurance General Hospital, Atsubetsu-chuo 2-6-2, Atsubetsu-ku, Sapporo, Hokkaido 004-8618, Japan.

Received for publication May 31, 2005.

Revised and accepted August 12, 2005. 
$4 \mathrm{~mm}$ in diameter. ${ }^{1,2)}$ The present study was designed to evaluate the clinical (9month) and angiographic (6-month) results of the ML PENTA stent in complex coronary lesions (modified American College of Cardiology/American Heart Association (ACC/AHA) lesion type $\mathrm{B} 2$ or $\mathrm{C})^{3,4)}$ and to determine independent factors correlated with target lesion revascularization.

\section{METHODS}

Design and patient population: This was a prospective, single center, nonrandomized study to evaluate the safety and efficacy of the ML PENTA stent, and to determine independent factors correlated with target lesion revascularization. The study population consisted of 86 consecutive patients who had undergone successful coronary ML PENTA stent implantation for coronary artery disease from May 2003 to July 2004. All patients enrolled provided written informed consent, and the study protocol was based on the regulations of the hospital's ethics committee.

Study patients had symptomatic ischemic heart disease attributable to a stenotic lesion. Patients with multivessel disease were permitted, however, only 1 lesion could be treated in the present study. The clinical characteristics, which included age, gender, coronary risk factors (hypertension, hypercholesterolemia, diabetes mellitus, smoking), indications for angioplasty, site of angioplasty, and drug treatment given after coronary stenting (nitrates, nicorandil, calcium antagonists, angiotensin-converting enzyme inhibitors, angiotensin-II receptor blockers, beta-blockers, antiplatelet agents, oral antidiabetics, and statins), are shown in Table I. Patients were defined as hypertensive if diastolic blood pressure was at least $90 \mathrm{mmHg}$ and/or systolic blood pressure was at least $140 \mathrm{mmHg}$, or if they were taking antihypertensive medication. Patients whose serum total cholesterol concentration was at least $220 \mathrm{mg} / \mathrm{dL}$ or who were taking antihypercholesterolemic medication were defined as having hypercholesterolemia. Patients whose fasting glucose concentration was at least $126 \mathrm{mg} / \mathrm{dL}$ and/or hemoglobin A1c at least $6.5 \%$ before drug or dietary treatment for at least 1 year prior to the present study or who were taking antidiabetic medication were defined as diabetic. Because a $75 \mathrm{~g}$-oral glucose tolerance test was not performed in all patients, diabetes mellitus was only diagnosed based on the fasting glucose concentration and hemoglobin A1c level. Fifty-six (65\%) patients had hypertension, 38 (44\%) hypercholesterolemia, 46 (54\%) non-insulin-dependent diabetes mellitus, and 37 $(43 \%)$ were smokers. Plasma concentrations of total cholesterol and triglycerides in the 38 hypercholesterolemic patients were $215 \pm 42 \mathrm{mg} / \mathrm{dL}$ and $148 \pm 61 \mathrm{mg} /$ $\mathrm{dL}$, respectively. The mean fasting glucose concentration and hemoglobin A1c 
Table I. Clinical Characteristics of Study Patients

\begin{tabular}{lc}
\hline $\mathrm{N}$ & 86 \\
Age (years) & $66.9 \pm 11.8$ \\
Gender, male (\%) & $51(59.3 \%)$ \\
Risk factors & \\
$\quad$ Hypertension (\%) & $56(65.1 \%)$ \\
Hypercholesterolemia (\%) & $38(44.2 \%)$ \\
$\quad$ Total cholesterol (mg/dL) & $215 \pm 42$ \\
$\quad$ Triglycerides (mg/dL) & $148 \pm 61$ \\
$\quad$ HDL cholesterol (mg/dL) & $49 \pm 16$ \\
Diabetes mellitus (\%) & $46(53.5 \%)$ \\
$\quad$ Fasting glucose concentration (mg/dL) & $151 \pm 40$ \\
$\quad$ Hemoglobin A1c (\%) & $7.1 \pm 1.3$ \\
Smoking (\%) & $37(43.0 \%)$ \\
Prior myocardial infarction (\%) & $5(5.8 \%)$ \\
Prior CABG (\%) & $6(7.0 \%)$ \\
Prior angioplasty (\%) & $6(7.0 \%)$ \\
Drug treatment after angioplasty & \\
Nitrates (\%) & $31(36.0 \%)$ \\
Nicorandil (\%) & $25(29.1 \%)$ \\
Ca-antagonist (\%) & $31(36.0 \%)$ \\
ACE-inhibitor or ARB (\%) & $41(47.7 \%)$ \\
Beta-blockers (\%) & $35(40.7 \%)$ \\
Antiplatelet agent (\%) & $86(100 \%)$ \\
Oral antidiabetic agent (\%) & $13(15.1 \%)$ \\
Insulin (\%) & $11(12.8 \%)$ \\
Statins (\%) & $28(32.6 \%)$ \\
\hline Values shown are meat &
\end{tabular}

Values shown are mean \pm SD or $n(\%)$.

ACE indicates angiotensin-converting enzyme; ARB, angiotensin II receptor blocker; and CABG, coronary artery bypass graft surgery.

level in the 46 diabetic patients were $151 \pm 40 \mathrm{mg} / \mathrm{dL}$ and $7.1 \pm 1.3 \%$, respectively (Table I).

Coronary stenting and quantitative coronary angiography: The angiographi characteristics of the subjects are summarized in Table II. Conventional balloon angioplasty was the only procedure carried out in all patients before stent implantation. Balloon or stent size and pressure were at the operator's discretion. Multiple stents were deployed if necessary to cover the full extent of the target lesion or dissection if it occurred. Procedural success was defined as the successful deployment of the stent and a residual stenosis less than $30 \%$ on quantitative coronary angiography. After stent implantation, adjunctive postdilation was performed using a high pressure balloon to achieve a residual stenosis less than $30 \%$. All patients received intravenous heparin $(100 \mathrm{IU} / \mathrm{kg})$ during the procedure and antiplatelet therapy (aspirin $100 \mathrm{mg} /$ day, and ticlopidine $200 \mathrm{mg} /$ day or cilostazol $200 \mathrm{mg} /$ day) for at least 3 months after the procedure. Quantitative coronary 
Table II. Angiographic Characteristics of Study Patients

\begin{tabular}{|c|c|}
\hline \multicolumn{2}{|l|}{ Indications for angioplasty } \\
\hline Stable angina $(\%)$ & $44(51.2 \%)$ \\
\hline Unstable angina $(\%)$ & $18(20.9 \%)$ \\
\hline Acute myocardial infarction $(\%)$ & $24(27.9 \%)$ \\
\hline Vessel disease (Single/Double/Triple) & $(42 / 27 / 17)$ \\
\hline Site of angioplasty (LAD/RCA/LCx/SVG) & $(44 / 27 / 12 / 3)$ \\
\hline \multicolumn{2}{|l|}{ ACC/AHA lesion type } \\
\hline $\mathrm{B} 2$ & $44(51.2 \%)$ \\
\hline Eccentric $(\%)$ & $79(91.9 \%)$ \\
\hline Calcification $(\%)$ & $46(53.5 \%)$ \\
\hline Bend $>45^{\circ}(\%)$ & $17(19.8 \%)$ \\
\hline Thrombus (\%) & $47(54.7 \%)$ \\
\hline Total occlusion $<3$ months $(\%)$ & $19(22.1 \%)$ \\
\hline Bifurcation lesion $(\%)$ & $26(30.2 \%)$ \\
\hline (1) & $42(48.8 \%)$ \\
\hline Lesion length $>2 \mathrm{~cm}(\%)$ & $42(48.8 \%)$ \\
\hline Tortuosity of proximal segment (\%) & $4(4.7 \%)$ \\
\hline Angulated segment $>90^{\circ}(\%)$ & $6(7.0 \%)$ \\
\hline Total occlusion > 3 months $(\%)$ & $2(2.3 \%)$ \\
\hline \multicolumn{2}{|l|}{ Postprocedural QCA } \\
\hline Reference (mm) & $2.98 \pm 0.44$ \\
\hline Minimal luminal diameter (mm) & $2.64 \pm 0.40$ \\
\hline Percent diameter stenosis (\%) & $11.2 \pm 7.6$ \\
\hline \multicolumn{2}{|c|}{$\begin{array}{l}\text { Values are shown as mean } \pm \text { SD or } n(\%) \text {. } \\
\text { ACC indicates American College of Cardiology; AHA, } \\
\text { American Heart Association; LAD, left anterior descend- } \\
\text { ing artery; LCx, left circumflex artery; QCA, quantitative } \\
\text { coronary angiography; RCA, right coronary artery; and } \\
\text { SVG, saphenous vein graft. }\end{array}$} \\
\hline
\end{tabular}

angiography was performed using a SIEMENS DCI-ACA imaging system. The contrast-filled guiding catheter was used as a reference. Intracoronary isosorbide dinitrate $(3 \mathrm{mg}$ ) was administered before all angiographic assessments. The diameters of the normal segments proximal and distal to the treated area were averaged to determine the reference diameter. The minimum lumen diameter and the percentage of diameter stenosis after coronary stenting were calculated by singleplane, worst-view angulation. Lesions requiring coronary stenting were characterized according to the modified ACC/AHA characteristics. ${ }^{3,4)}$

Clinical and angiographic follow-up: All patients underwent follow-up coronary angiography. Target lesion revascularization was indicated by the presence of clinical or functional ischemia and more than $75 \%$ diameter stenosis or a restenosed lesion more than $90 \%$ in the absence of documented ischemia. Angiographic restenosis was defined as the incidence of percent diameter stenosis > $50 \%$ at follow-up angiography. Clinical follow-up data were obtained from either hospital records or by telephone contact with the patient or referring physician. 
Cardiac events were defined as cardiac death, myocardial infarction, coronary artery bypass graft surgery, repeat coronary angioplasty of the target lesion, and nonstented lesions. In-hospital events were included in the analysis of follow-up events.

Statistical analysis: All data are expressed as the mean \pm SD. The difference in mean values between the 2 groups was compared using an unpaired t test. The incidences in the 2 groups were compared using the chi-square test. To determine independent explanatory factors correlated with target lesion revascularization and cardiac events, SPSS Advanced Statistics 10.0 package for Macintosh (SPSS Japan, Inc.) was used. Multiple logistic regression analysis was indicated after confirmation of several statistically significant factors by single logistic regression analysis, and the odds ratio with a $95 \%$ confidence interval was calculated. Coronary risk factors (presence or absence), ACC/AHA lesion type (B2 or C), lesion length ( $\leq 20 \mathrm{~mm}$ or $>20 \mathrm{~mm})$, percent diameter stenosis $(\leq 20 \%$ or $>20 \%)$, reference diameter $(<3.0 \mathrm{~mm}$ or $\geq 3.0 \mathrm{~mm}$ ), stent number (single or multiple), high pressure balloon use (used or not), and drug treatment (drug(s) taken after coronary stenting or not) were included as factors in the multiple logistic regression analysis. A $P$ value less than 0.05 was considered significant.

\section{RESULTS}

Tables I and II show the clinical and angiographic characteristics, respectively, of the patients, while Table III presents the cardiac events observed during the follow-up period. Two $(2.3 \%)$ of the 86 patients developed acute myocardial

Table III. Cardiac Events During Follow-up Period

\begin{tabular}{lc}
\hline Any event & $21(24.4 \%)$ \\
Death & $0(0 \%)$ \\
Cardiac & $0(0 \%)$ \\
Noncardiac & $0(0 \%)$ \\
Myocardial infarction & $2(2.3 \%)$ \\
Angiographical restenosis $(>50 \%)$ & $17(19.8 \%)$ \\
Repeat revascularization & $20(23.3 \%)$ \\
TLR & $16(18.6 \%)$ \\
Repeat angioplasty only & $14(16.3 \%)$ \\
CABG only & $1(1.2 \%)$ \\
Repeat angioplasty and CABG & $1(1.2 \%)$ \\
New lesion & $4(4.7 \%)$ \\
Angioplasty & $2(2.3 \%)$ \\
CABG & $2(2.3 \%)$ \\
Any cardiac event & $21(24.4 \%)$ \\
\hline
\end{tabular}

Values are shown as $n(\%)$.

CABG indicates coronary artery bypass graft surgery and

TLR, target lesion revascularization. 
Table IV. Comparison of Clinical and Angiographic Parameters Between Patients With and Without TLR

\begin{tabular}{|c|c|c|c|}
\hline & Without TLR & With TLR & $P$ value \\
\hline $\mathrm{N}$ & 70 & 16 & \\
\hline Age (years) & $66.8 \pm 12.4$ & $67.3 \pm 9.2$ & NS \\
\hline Gender, male $(\%)$ & $41(58.6 \%)$ & $10(62.5 \%)$ & NS \\
\hline \multicolumn{4}{|l|}{ Risk factors } \\
\hline Hypertension (\%) & $48(68.6 \%)$ & $8(50.0 \%)$ & NS \\
\hline Hyperlipidemia (\%) & $31(44.3 \%)$ & $7(43.8 \%)$ & NS \\
\hline Total cholesterol $(\mathrm{mg} / \mathrm{dL})$ & $194 \pm 40$ & $203 \pm 33$ & NS \\
\hline Triglycerides (mg/dL) & $123 \pm 54$ & $133 \pm 51$ & NS \\
\hline HDL cholesterol (mg/dL) & $45 \pm 14$ & $46 \pm 17$ & NS \\
\hline Diabetes mellitus (\%) & $35(50.0 \%)$ & $11(68.8 \%)$ & NS \\
\hline Fasting glucose concentration $(\mathrm{mg} / \mathrm{dL})$ & $123 \pm 35$ & $133 \pm 59$ & NS \\
\hline Smoking $(\%)$ & $30(42.9 \%)$ & $7(43.8 \%)$ & NS \\
\hline Multivessel (\%) & $37(52.9 \%)$ & $7(43.8 \%)$ & NS \\
\hline $\operatorname{AMI}(\%)$ & $18(25.7 \%)$ & $6(37.5 \%)$ & NS \\
\hline \multicolumn{4}{|l|}{ Angioplasty } \\
\hline Multistent (\%) & $18(25.7 \%)$ & $9(56.3 \%)$ & 0.038 \\
\hline Lesion length $>2 \mathrm{~cm}(\%)$ & $30(42.9 \%)$ & $12(75.0 \%)$ & 0.041 \\
\hline Reference $<3.0 \mathrm{~mm}$ & $42(60.0 \%)$ & $11(68.8 \%)$ & NS \\
\hline Percent DS > 20\% (\%) & $2(2.9 \%)$ & $5(31.3 \%)$ & 0.001 \\
\hline ACC/AHA lesion type C (\%) & $33(47.1 \%)$ & $9(56.3 \%)$ & NS \\
\hline Maximal balloon pressure (atm) & $10.3 \pm 2.2$ & $10.1 \pm 2.9$ & NS \\
\hline High pressure balloon use $(\%)$ & $13(18.6 \%)$ & $3(18.8 \%)$ & NS \\
\hline \multicolumn{4}{|l|}{ Drug treatment after angioplasty } \\
\hline ACE-inhibitor or ARB (\%) & $33(47.1 \%)$ & $8(50.0 \%)$ & NS \\
\hline Nicorandil (\%) & $21(30.0 \%)$ & $3(18.8 \%)$ & NS \\
\hline Ca-antagonist $(\%)$ & $26(37.1 \%)$ & $5(31.3 \%)$ & NS \\
\hline Beta-blocker $(\%)$ & $31(44.3 \%)$ & $4(25.0 \%)$ & NS \\
\hline Oral antidiabetic (\%) & $11(15.7 \%)$ & $2(12.5 \%)$ & NS \\
\hline Insulin $(\%)$ & $8(11.4 \%)$ & $3(18.8 \%)$ & NS \\
\hline Statins (\%) & $23(32.9 \%)$ & $5(31.3 \%)$ & NS \\
\hline
\end{tabular}

Values are shown as mean \pm SD or n (\%). ACC indicates American College of Cardiology; ACE, angiotensin-converting enzyme; AHA, American Heart Association; AMI, acute myocardial infarction; ARB, angiotensin II receptor blocker; DS, diameter stenosis; NS, no significance; and TLR, target lesion revascularization.

infarction during follow-up. Late thrombosis at the stented lesion occurred in one patient 52 days after stent implantation and repeat angioplasty was performed. One patient developed a right coronary artery-related acute myocardial infarction 5 months after stent implantation in the left anterior descending artery. Cardiac events were documented in 21 (24.4\%) of the 86 patients, and $17(19.8 \%)$ of the 86 patients underwent repeat angioplasty. Follow-up coronary angiography was performed in all 86 patients. Target lesion revascularization was required in 16 (18.6\%). Table IV shows a comparison of the patient groups with and without target lesion revascularization. The target lesion revascularization group had a greater prevalence of lesion length $>2.0 \mathrm{~cm}(P=0.041)$, percent diameter steno- 
Table V. Single and Multiple Logistic Regression Analysis on Target Lesion Revascularization

\begin{tabular}{lcccc}
\hline Variables & Standard error & Chi-square (Wald) & $P$ Value & Odds ratio (95\%CI) \\
\hline Single logistic & & & & \\
$\quad$ Lesion length $>2 \mathrm{~cm}$ & 0.626 & 4.907 & 0.0268 & $4.000(1.173-13.640)$ \\
$\quad$ Multistent & 0.573 & 5.237 & 0.0221 & $3.714(1.207-11.428)$ \\
$\quad$ Percent DS $>$ 20\% & 0.898 & 9.305 & 0.0023 & $15.455(2.661-89.771)$ \\
$\quad$ Multiple logistic & & & & \\
$\quad$ Percent DS $>$ 20\% & 0.981 & 6.234 & 0.0125 & $11.585(1.207-79.278)$ \\
\hline
\end{tabular}

CI indicates confidence interval and DS, diameter stenosis.
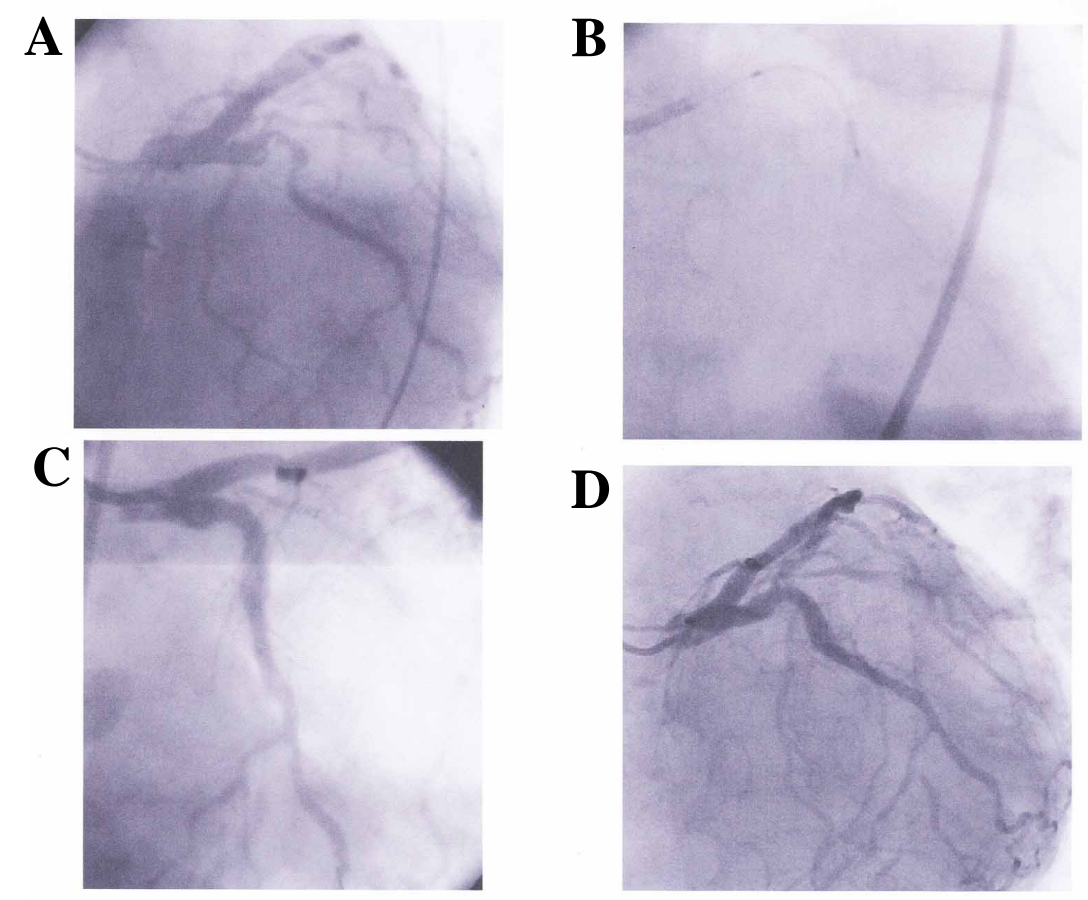

Figure. Left coronary angiogram. A: Left coronary angiogram in the $10^{\circ}$ right anterior oblique and $25^{\circ}$ caudal projection demonstrated severe stenosis and excessive tortuosity with thrombus. B: After balloon dilatation, although residual percent diameter stenosis was $>20 \%$, we succeeded in the $3.5 \times 23 \mathrm{~mm}$ ML PENTA stent deployment. C: Left coronary angiogram in the $30^{\circ}$ right anterior oblique and $25^{\circ}$ caudal projection after ML PENTA stent implantation. D: Follow-up left coronary angiogram in the $10^{\circ}$ right anterior oblique and $25^{\circ}$ caudal projection at 6 months showed no restenosis.

sis $>20 \%(P=0.001)$, and multiple stents $(P=0.038)$ compared to the no target lesion revascularization group. Single logistic regression analysis showed that target lesion revascularization was significantly correlated with lesion length > $2.0 \mathrm{~cm}$, percent diameter stenosis $>20 \%$, and multiple stents, but not with coro- 
nary risk factors, indications for angioplasty, ACC/AHA lesion type $\mathrm{C}$, high pressure balloon use, or drug treatment after coronary stenting. Multiple logistic regression analysis revealed that percent diameter stenosis $>20 \%(P=0.0125$, odds ratio $=11.585)$ was the significant explanatory factor of target lesion revascularization (Table V).

Case presentation: A 68-year-old female was admitted to our hospital with angina pectoris. She was undergoing hemodialysis due to diabetic nephropathy that had developed 7 years earlier. A coronary angiogram showed severe stenosis in the left circumflex artery, and the stenotic lesion exhibited excessive tortuosity with thrombus (Figure 1A). We performed catheter intervention using a 6 French Judkins type guiding catheter. After balloon dilatation, we succeeded in deploying the ML PENTA stent $(3.5 \times 23 \mathrm{~mm})$ (Figure 1B, C). After 6 months, followup angiography showed no restenosis (Figure 1D). Good flexibility and conformability of the ML PENTA stent were observed in this case.

\section{DISCUSSION}

The results of the present study suggest that 9-month clinical and 6-month angiographic outcomes in patients with coronary artery disease treated by the ML PENTA stent were excellent, with a low target lesion revascularization rate, and target lesion revascularization after coronary ML PENTA stent implantation was influenced by residual percent diameter stenosis.

Clinical and angiographic outcomes after coronary ML PENTA stent implantation: The flexibility of the ML PENTA stent platform with variable strut thicknesses $(0.09-0.12 \mathrm{~mm})$ and a modified link pattern was improved to facilitate safe delivery and conformability in complex coronary lesions and maintain side-branch access with the possibility to expand the cell toward the side branch up to $4 \mathrm{~mm}$ in diameter. ${ }^{1,2)}$ The DELIVER trial using the ML PENTA stent reported good clinical and angiographic results; target vessel failure (death, Q-wave or non-Qwave myocardial infarction, target lesion revascularization) was $14.5 \%$ at 9 months and stent binary restenosis was $20.6 \%$ at 8 months. ${ }^{1)}$ In the present study, although 46 (54\%) patients had diabetes mellitus and the ACC/AHA lesion characteristics of the stented lesion were all $\mathrm{B} 2$ or $\mathrm{C}$, the rate of target lesion revascularization was $18.6 \%$ and the rate of cardiac events was $24.4 \%$ at 9 months. We previously reported on the angiographic restenosis rates of the Palmaz-Schatz (PS) stent (Cordis Corporation, Miami, Florida) and ACS ML stent (Guidant Corporation, Santa Clara, California). ${ }^{5)}$ The angiographic restenosis rates for ACC/AHA lesion type A or B1 were significantly lower than those of lesion type $\mathrm{B} 2$ or $\mathrm{C}$ for both the PS and ML stents. That is, the angiographic restenosis rates for ACC/AHA lesion type A or B1 were $8.3 \%$ in both the PS and ML stents, and 
$35.7 \%$ for the PS stent and 39.3\% for the ML stent for ACC/AHA lesion type B2 or $\mathrm{C}$. These findings, as well as those of previous studies, suggest that clinical and angiographic outcomes in patients with coronary artery disease treated with successful coronary ML PENTA stent implantation are favorable.

Predictive factors of target lesion revascularization: Multiple stents, small vessel $(<3.0 \mathrm{~mm})$, lesion length, coronary risk factors, and stented segment length have been reported to be predictive factors of major adverse cardiac events after coronary stenting. ${ }^{6-10)}$ However, in the present study, lesion length and small vessel were not identified as predictors of target lesion revascularization. Thus, based on the results of the present study, the ML PENTA stent may be superior with respect to long lesions or small vessels.

In the present study, residual percent diameter stenosis after stenting was found to be an independent predictive factor of target lesion revascularization. We previously reported a similar finding, ${ }^{11)}$ and other studies have also shown that a small minimum lumen diameter or a small percent diameter stenosis after the procedure are predictive factors of major adverse cardiac events after coronary stenting. ${ }^{12,13)}$ Therefore, since the final result (residual diameter stenosis) after coronary stenting should be one of the most important factors for target lesion revascularization, interventional cardiologists should achieve the optimal final diameter stenosis $(\leq 20 \%)$ after stenting in order to avoid target lesion revascularization. In the present study, we achieved a final diameter stenosis of $\leq 20 \%$ in $79(91.9 \%)$ of the 86 patients. This is most likely one of the reasons for the excellent clinical and angiographic results.

Strategies for complex coronary lesions: We previously reported that ACC/AHA lesion type was identified as an independent predictor of cardiac events after coronary stent implantation. ${ }^{5,11)}$ Recently, favorable results with drug-eluting stents for the treatment of de novo coronary lesions, including complex coronary lesions, have been reported. ${ }^{14)}$ Drug-eluting stents should be improved in the future to reduce in-stent restenosis, however, it is often difficult to cross the Sirolimus-coated Bx-Velocity stent (Cypher; Cordis, Johnson \& Johnson) through an extremely angulated segment or tortuous lesion. The ML PENTA stent may be very useful for stenting tortuous or angulated lesions that are difficult to cross for the Sirolimus-coated Bx-Velocity stent.

Study limitations: The present study has several limitations. The results from the 86 consecutive patients (acute myocardial infarction in 24 patients, unstable angina in 18 patients, and stable angina in 44 patients) strongly suggest the need for a larger patient population. Our study did not include a comparison group of patients treated with standard balloon angioplasty without stenting or a different type of stent. Further studies using a larger patient population are therefore needed to evaluate the safety and efficacy of the ML PENTA stent in complex 
coronary lesions and to determine independent factors correlated with target lesion revascularization.

\section{ACKNOWLEDGEMENT}

We are deeply grateful to the staff of the catheter laboratory in our hospital for their excellent technical assistance.

\section{REFERENCES}

1. Lansky AJ, Costa RA, Mintz GS, et al. Non-polymer-based paclitaxel-coated coronary stents for the treatment of patients with de novo coronary lesions: angiographic follow-up of the DELIVER clinical trial. Circulation 2004; 109: 1948-54.

2. Colombo A, Stankovic G, Moses JW. Selection of coronary stents. J Am Coll Cardiol 2002; 40: 1021-33. (Review)

3. Ryan TJ, Faxon DP, Gunnar RM, et al. Guidelines for percutaneous transluminal coronary angioplasty. A report of the American College of Cardiology/American Heart Association Task Force on Assessment of Diagnostic and Therapeutic Cardiovascular Procedures (Subcommittee on Percutaneous Transluminal Coronary Angioplasty). J Am Coll Cardiol 1988; 12: 529-45.

4. Ellis SG, Vandormael MG, Cowley MJ, et al. Coronary morphologic and clinical determinants of procedural outcome with angioplasty for multivessel coronary disease. Implications for patient selection. Multivessel Angioplasty Prognosis Study Group. Circulation 1990; 82: 1193-202.

5. Sasao H, Endo A, Hasegawa T, Oimatsu H, Takada T. Comparison of three-year clinical outcome of the multilink stent with the Palmaz-Schatz stent in Japanese patients with coronary artery disease: a case control study. $\mathrm{J}$ Invasive Cardiol 2003; 15: 433-6.

6. Akiyama T, Moussa I, Reimers B, et al. Angiographic and clinical outcome following coronary stenting of small vessels: a comparison with coronary stenting of large vessels. J Am Coll Cardiol 1998; 32: 1610-8.

7. Kastrati A, Schomig A, Elezi S, et al. Predictive factors of restenosis after coronary stent placement. J Am Coll Cardiol 1997; 30: 1428-36.

8. Suselbeck T, Latsch A, Siri H, et al. Role of vessel size as a predictor for the occurrence of in-stent restenosis in patients with diabetes mellitus. Am J Cardiol 2001; 88: 243-7.

9. Kereiakes D, Linnemeier TJ, Baim DS, et al. Usefulness of stent length in predicting in-stent restenosis (the MULTI-LINK stent trials). Am J Cardiol 2000; 86: 336-41.

10. Violaris AG, Thury A, Regar E, Melkert R, Serruys PW. Influence of a history of smoking on short term (six month) clinical and angiographic outcome after successful coronary angioplasty. Heart 2000; 84: 299-306.

11. Sasao H, Endo A, Hasegawa T, et al. Long-term follow-up after coronary stent implantation in patients with coronary artery disease. Angiology 2002; 53: 149-56.

12. Kuntz RE, Safian RD, Carrozza JP, Fishman RF, Mansour M, Baim DS. The importance of acute luminal diameter in determining restenosis after coronary atherectomy or stenting. Circulation 1992; 86: 1827-35.

13. Strauss BH, Serruys PW, de Scheerder IK, et al. Relative risk analysis of angiographic predictors of restenosis within the coronary Wallstent. Circulation 1991; 84: 1636-43.

14. Moses JW, Leon MB, Popma JJ, et al. Sirolimus-eluting stents versus standard stents in patients with stenosis in native coronary artery. N Engl J Med 2003; 349: 1315-23. 